\title{
Nucleolin Is a Receptor for Maleylated-Bovine Serum Albumin on Macrophages
}

\author{
Yuichi Miki,* Keisuke Koyama, Haruna Kurusu, Kazuya Hirano, Masatoshi Beppu, and \\ Yasuyuki Fujiwara \\ School of Pharmacy, Tokyo University of Pharmacy and Life Sciences; 1432-1 Horinouchi, Hachioji, Tokyo 192- \\ 0392, Japan.
}

Received September 1, 2014; accepted October 15, 2014

\begin{abstract}
Scavenger receptors have a broad range of functions that include pathogen clearance, and identification of the scavenger receptor family has been of great benefit to the field of physiology. The shuttling-protein nucleolin has recently been shown to possess scavenger receptor-like activity. We therefore investigated whether or not nucleolin is a receptor for maleylated-bovine serum albumin (maleylated-BSA), which is a common ligand for scavenger receptors. Binding and phagocytosis of native control-BSA by thioglycollateelicited mouse peritoneal macrophages was weak, but that of maleylated-BSA was strong. Surface plasmonresonance analysis revealed that nucleolin strongly associated with maleylated-BSA but not control-BSA or maleic anhydride. Further, co-treatment of macrophages with anti-nucleolin antibody, but not control-immunoglobulin G, inhibited binding of maleylated-BSA. In addition, antineoplastic guanine rich oligonucleotide (AGRO), a nucleolin-specific oligonucleotide aptamer, inhibited binding of maleylated-BSA. Further, binding of maleylated-BSA to nucleolin-transfected HEK293 cells was higher than that by control HEK cells. These results indicate that nucleolin is a receptor that enables macrophages to recognize maleylated-BSA.
\end{abstract}

Key words macrophage; maleylated-bovine serum albumin; nucleolin; scavenger receptor

Macrophages rapidly recognize and remove physiologically or chemically modified proteins, lipids, lipoproteins, and cells to maintain tissue homeostasis. Failure to remove these components results in their accumulation, injury to surrounding tissues, disease, and abnormal autoimmune responses that potentially trigger a number of functional disorders. Therefore, macrophages are critical for maintaining homeostasis and healthy tissues by clearing various discarded elements and reducing inflammation. ${ }^{1-4)}$

Scavenger receptors (SRs) consist of classes A to I and are expressed on the surfaces of macrophages, dendritic cells, and endothelial cells and initiate the removal of a large repertoire of discarded elements. SRs were identified by their ability to recognize and remove modified or damaged proteins (e.g. $\beta$-amyloid), lipoproteins (e.g. oxidized low density lipoprotein (LDL)), lipid (e.g. oxidized phosphatidylserine), and damaged cells (e.g. apoptotic cells). ${ }^{3)}$ The affinity of SRs for endogenous elements is involved in the pathogenesis of multiple diseases. For example, SRs participate in the binding and internalization of amyloid $\beta 42$, oxidized LDL, and in the transport of fatty acids. SRs have also been implicated in diseases as diverse as Alzheimer's disease, atherosclerosis and type 2 diabetes mellitus. ${ }^{3)}$

In addition to modified endogenous molecules, SRs recognize conserved pathogen-associated molecular patterns (PAMPs) expressed on exogenous microbial surfaces, which results in the clearance of various microbial species and structures such as bacteria and bacterial lipopolysaccharides, lipoteichoic acid, CpG DNA and viruses. ${ }^{3)}$ SRs therefore have a broad range of functions including not only the binding of modified self-molecules [danger-associated molecular patterns (DAMPs)], but also that of several exogenous PAMPs. ${ }^{3,5}$ ) These findings suggest that SRs have a wide range of functions and that the identification of members of the scavenger receptor family might help characterize tissue homeostasis and diseases.

Nucleolin is present in the nucleus, cytoplasm, and surface of macrophages. ${ }^{6)}$ Our previous studies have shown that macrophages utilize nucleolin to recognize and phagocytose discarded elements, including amyloid $\beta 42,{ }^{7)}$ glycated proteins, ${ }^{4}$ apoptotic $^{8)}$ and oxidized cells, ${ }^{9)}$ to maintain tissue homeostasis. In addition, nucleolin is also a receptor for microbes and their substituents, including lipopolysaccharide, ${ }^{10)}$ enterohemorrhagic Escherichia (E.) coli O157:H7, ${ }^{11)}$ human parainfluenza virus type $3,{ }^{12}$ ) human immunodeficiency virus ${ }^{13)}$ and coxsackie B virus. ${ }^{14)}$ Taken together, these observations suggest that macrophages expressing nucleolin on their surface might have a general scavenger-like ability.

SRs generally have affinity for polyanionic molecules. ${ }^{15)}$ Maleylated protein derivatives, such as maleylated-bovine serum albumin (maleylated-BSA), have excess negative charge and are ligands for SRs on macrophages. ${ }^{16,17)}$ Maleylated-BSA induces various physiological effects in macrophages, including tumor necrosis factor (TNF)- $\alpha$, interleukin- $\beta$, and nitric oxide production. ${ }^{17,18)}$ However, the molecular mechanisms underlying these effects of maleylated-BSA on macrophage function are unclear. In addition, whether or not macrophage cell surface nucleolin recognizes maleylated-BSA is unknown. Here, we investigated whether or not nucleolin is a receptor for maleylated-BSA.

\section{MATERIALS AND METHODS}

Materials BSA and PKH 26 red fluorescent cell-linker kits were obtained from Sigma-Aldrich (St. Louis, MO, U.S.A.). Alexa Fluor $^{\circledR} 488$ C5 maleimide was obtained from Life Technologies (Carlsbad, CA, U.S.A.). rNUC284, a truncated recombinant human nucleolin containing residues 
284-710 and corresponding to the C-terminal and two-thirds of the molecule, was produced in E. coli and purified as previously described. ${ }^{8)}$ Phycoerythrin-labeled anti-CD11b antibody was obtained from BD Pharmingen (Tokyo, Japan). Anti-nucleolin antibody was obtained from Bethyl Laboratories, Inc. (Montgomery, AL, U.S.A.). Control-rabbit immunoglobulin $\mathrm{G}$ ( $\mathrm{IgG}$ ) was obtained from Santa Cruz Biotechnology (Delaware, CA, U.S.A.).

Preparation of Maleylated-BSA Maleylated-BSA was prepared as described by Butler and Hartley. ${ }^{16)}$ Briefly, maleic anhydride powder was added to BSA $(5 \mathrm{mg} / \mathrm{mL})$ in $0.2 \mathrm{M}$ $\mathrm{Na}_{2} \mathrm{~B}_{4} \mathrm{O}_{7}$ and $\mathrm{pH}$ maintained at 8.5 by $\mathrm{Na}_{2} \mathrm{CO}_{3}$. Addition of maleic anhydride was terminated once there was no decrease in $\mathrm{pH}$. After incubation, the sample was dialysed 6 times with 100 times the volume of $\mathrm{Ca}^{2+}, \mathrm{Mg}^{2+}$-free Dulbecco's phosphate-buffered saline (DPBS $[-]$ ) at $4^{\circ} \mathrm{C}$ to remove lowmolecular-weight reactants and maleic anhydride, and protein concentration was measured via the Lowry method. ${ }^{19)}$ Trinitrobenzene sulfonic acid titration ${ }^{20}$ confirmed that $95.2 \%$ of free amino groups in maleylated-BSA preparation was modified, compared to native-BSA.

Fluorescent Labeling of Control-BSA and MaleylatedBSA Using Alexa Fluor $^{\circledR} 488$ C5 Maleimide Control-BSA or maleylated-BSA was incubated with 20 times the volume of Alexa Fluor ${ }^{\circledR} 488 \mathrm{C} 5$ maleimide overnight at $4^{\circ} \mathrm{C}$ in DPBS(-) under nitrogen replacement and then dialysed 6 times with 100 times the volume of $\operatorname{DPBS}(-)$. Protein concentrations were measured via the Lowry method, ${ }^{19)}$ and fluorescence intensities were measured using a VARIOSKAN microspectrometer (excitation: $492 \mathrm{~nm}$, emission: $519 \mathrm{~nm}$ ). The strengths of Alexa-control-BSA, Alexa-maleylated-BSA fluorescence per unit dosage were each adjusted by adding unlabeled proteins.

Binding of Control-BSA and Maleylated-BSA to Mouse Macrophages The protocol was approved by the committee on the Ethics of Animal Experiments of Tokyo University of Pharmacy and Life sciences (Permit Number: P14-15). All surgery was performed under diethyl ether anesthesia, and all efforts were made to minimize suffering.

Thioglycollate-elicited mouse macrophages were prepared from male ddy mice (Japan SLC, Inc., Shizuoka, Japan), as previously described. ${ }^{4,8,21)}$ Macrophages were suspended at $5 \times 10^{5}$ cells $/ \mathrm{mL}$ in RPMI-1640 medium buffered with $20 \mathrm{~mm}$ 4-[2-hydroxyethy]1-piperazineethanesulfonic acid (RPMI 1640-HEPES, $\mathrm{pH}$ 7.2) and then incubated with $0-20 \mu \mathrm{g} /$ mL Alexa Fluor ${ }^{\circledR}$ 488-labeled control-BSA or maleylatedBSA at $37^{\circ} \mathrm{C}$ for $2 \mathrm{~h}$. After $2 \mathrm{~h}$, the cells were incubated with phycoerythrin-labeled anti-CD11b antibody for $30 \mathrm{~min}$ on ice, then washed and immediately analyzed using a flow cytometer (FACS Calibur, Becton-Dickinson, Franklin Lakes, NJ, U.S.A.) with CellQuest software (Becton-Dickinson) and gating for forward scatter (FSC) and side scatter (SSC) regions of intact cells. Since fluorescent labeled anti-CD11b was used for selection of macrophages at flow cytometer analysis, antiCD11b positive cells were regarded as macrophages. ${ }^{4,8,21)}$

Confocal Images of Phagocytosed Maleylated-BSA Macrophages were seeded on a coverslip as previously described $^{8)}$ and incubated with $0-10 \mu \mathrm{g} / \mathrm{mL}$ Alexa Fluor ${ }^{\circledR}$ 488-labeled control-BSA or maleylated-BSA, and membranes were stained with the fluorescent cell-linker compound $\mathrm{PKH}$ 26 red. BSAs taken up by macrophages were identified using confocal laser-scanning fluorescence microscopy (FV1000D; Olympus, Tokyo, Japan).

Surface Plasmon-Resonance (Biacore) Binding of nucleolin to control-BSA or maleylated-BSA was analyzed using a Biacore 2000X (GE Healthcare, Tokyo, Japan). This biosensor directly measures the binding of a recombinant protein to its ligand in real time and in a quantitative and highly reproducible manner. ${ }^{22)}$ Briefly, DPBS(-) was used for sample dilution and analysis. rNUC284 was produced in E. coli and purified as previously described ${ }^{8)}$ and immobilized on a research-grade CM5 dextran sensor-chip. ${ }^{4)}$ To evaluate binding, control-BSA or maleylated-BSA were diluted in $\operatorname{DPBS}(-)$, analyzed at different concentrations, and passed over the sensor chip at a flow rate of $20 \mu \mathrm{L} / \mathrm{min}$. An activated and blocked flow-cell without immobilized ligands was used to evaluate nonspecific binding. Results were calculated using BIAevaluation 4.0 software (Biacore).

SDS-PAGE Analysis BSAs $(17 \mu \mathrm{g})$ were analyzed via sodium dodecyl sulfate polyacrylamide gel electrophoresis (SDS-PAGE) as described by Laemmli, using a 10\% polyacrylamide gel under reducing conditions. ${ }^{23)}$

Binding of Maleylated-BSA to Nucleolin-Transfected HEK Cells Human nucleolin cDNA was transfected into the monolayer of HEK 293 cells (HEK cells) (Health Science Research Bank, Osaka, Japan) as previously described. ${ }^{8)}$ Sixteen hours after transfection, adherent HEK cells were dislodged by incubation with Puck's ethylenediaminetetraacetic acid (EDTA) solution (5 mM $N$-(2-hydroxyethyl)perazine- $N^{\prime}-2$ ethanesulfonic acid (HEPES), $0.1 \mathrm{M} \mathrm{NaCl}, 5 \mathrm{~mm} \mathrm{KCl}, 4 \mathrm{~mm}$ $\mathrm{NaHCO}_{3}, 1 \mathrm{~mm}$ EDTA, and $5.6 \mathrm{~mm}$ glucose) for $10 \mathrm{~min}$ and gentle pipetting. HEK cells were then incubated with $10 \mu \mathrm{g} /$ $\mathrm{mL}$ Alexa Fluor ${ }^{\circledR} 488$-labeled maleylated-BSA at $37^{\circ} \mathrm{C}$ for $2 \mathrm{~h}$ and immediately analyzed using a flow cytometer with CellQuest software with gating for FSC and SSC regions of intact HEK cells.

Statistical Analysis Data are presented as the mean \pm standard deviation (S.D.) of at least triplicate determinants and were analyzed using Student's $t$-tests.

\section{RESULTS}

Maleylated-BSA Was Bound and Phagocytosed by Macrophages The purpose of present study was to elucidate whether or not nucleolin is a receptor for maleylated-BSA. First, we compared the proportion of macrophages that bound and phagocytosed maleylated-BSA and native-BSA. Although mouse macrophages did not bind control-BSA (Fig. 1A, open circle), they did bind maleylated-BSA in a dose-dependent manner (closed circle). The binding of Alexa Fluor ${ }^{\circledR} 488$ labeled maleylated-BSA was suppressed by unlabeled maleylated-BSA dose-dependently (Fig. 1B), suggesting that Alexa Fluor $^{\circledR} 488$ labeled maleylated-BSA was specifically binding to macrophages. In addition, although macrophages did not exhibit a high level of phagocytosis for control-BSA (Figs. 2B, D), they did for maleylated-BSA (Figs. 2C, D), indicating that they regard maleylated modified-protein as a target for removal.

Binding of Nucleolin with Maleylated-BSA We next investigated whether or not nucleolin is a receptor for maleylated-BSA. We first observed the interactions between nucleolin and maleylated-BSA using surface plasmon-resonance (SPR). 
A

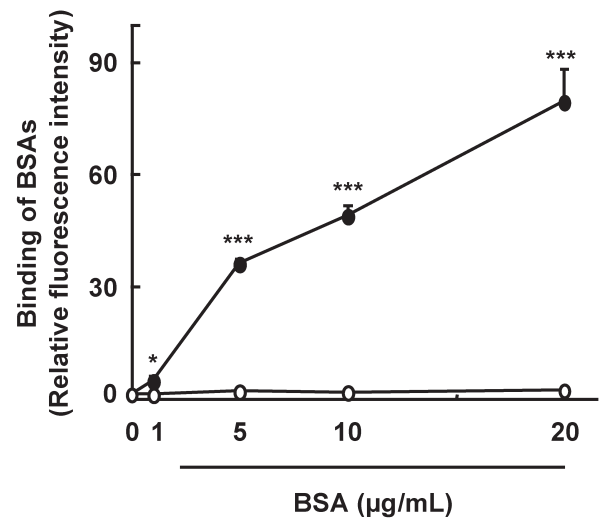

B

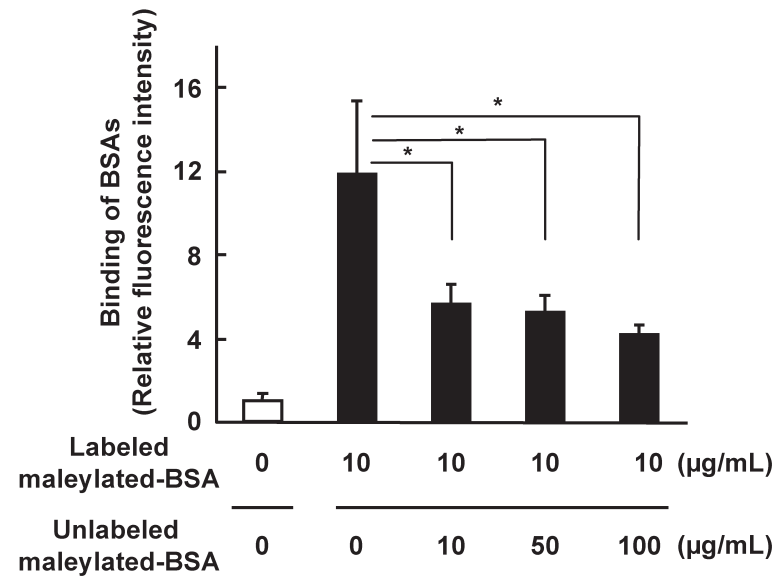

Fig. 1. Binding of Maleylated-BSA to Macrophages

(A) Binding of $0-20 \mu \mathrm{g} / \mathrm{mL}$ Alexa Fluor ${ }^{\circledR} 488$-labeled control-BSA (open circle) and maleylated-BSA (closed circle) to macrophages as measured by the mean fluorescence intensity (flow cytometer analysis). (B) Co-incubation with $0-100 \mu \mathrm{g} / \mathrm{mL}$ unlabeled maleylated-BSA suppressed binding of $10 \mu \mathrm{g} / \mathrm{mL}$ Alexa Fluor ${ }^{\circledR} 488-1 a b e l e d$ maleylated-BSA. Each point represents the mean \pm S.D. of triplicate determinations. ${ }^{*} p<0.05 ; * * * p<0.001$

A

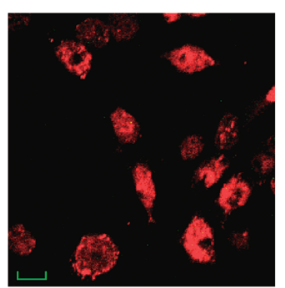

B

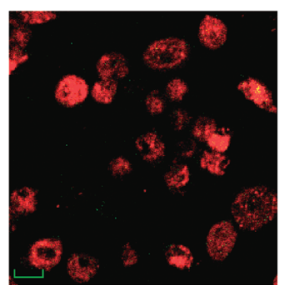

C

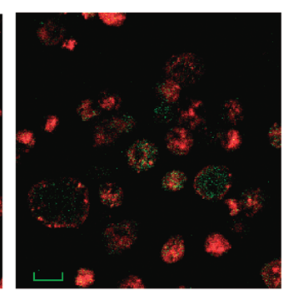

Bar: $10 \mu \mathrm{m}$

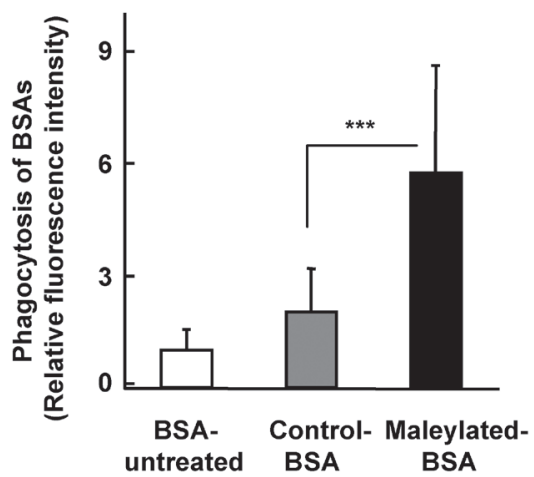

Fig. 2. Phagocytosis of Maleylated-BSA by Macrophages

Phagocyotsis of Alexa Fluor ${ }^{\circledR} 488$-labeled control-BSA, $10 \mu \mathrm{g} / \mathrm{mL}$ (B) and maleylated-BSA, $10 \mu \mathrm{g} / \mathrm{mL}$ (C) by macrophages was observed by confocal laser microscopic analysis. BSA-untreated macrophage (A) is shown as a control image. Green, BSAs. Red, macrophage cell-surface. (D) Relative fluorescence intensities of intracellular green-fluorescence. Columns represent mean \pm S.D. $* * * p<0.001$.

rNUC284, a truncated recombinant human nucleolin containing residues 284-710 and corresponding to the C-terminal and two-thirds of the molecule, was produced in E. coli and purified as previously described. ${ }^{8)}$ We used native-BSA as an affinity control, as we have previously shown that native-BSA was not bound to rNUC284. ${ }^{4)}$ Control-BSA, maleic anhydride, and maleylated-BSA were applied to a CM5 dextran sensorchip, which was immobilized with rNUC284. The sensorgram demonstrated that maleylated-BSA had a high concentrationdependent affinity and did not easily dissociate upon washing (Fig. 3C), while control-BSA (Fig. 3A) and maleic anhydride (Fig. 3B) had no affinity for rNUC284. SDS-PAGE analysis showed that the molecular weight of control-BSA and maleylated-BSA were calculated as $61.3 \mathrm{kDa}(77 \mathrm{~mm}$ of electrophoretic mobility) and $88.4 \mathrm{kDa}(54 \mathrm{~mm}$ of electrophoretic mobility) (Fig. 3D). Therefore, the respective $k_{\mathrm{a}}, k_{\mathrm{d}}$, and $K D$ values between rNUC284 and each BSA were calculated as follows: maleylated-BSA: $7.62 \times 10^{2}, 2.08 \times 10^{-2}$ and $3.69 \times 10^{-4}$, control-BSA: $k_{\mathrm{a}}=2.86\left(k_{\mathrm{d}}\right.$ and $K D$ value were not shown, since control-BSA was hardly shown the affinity for rNUC284). These results indicate that maleylated-BSA bound to nucleolin and that control-BSA and maleic anhydride did not.

Involvement of Macrophage-Surface Nucleolin in Binding of Maleylated-BSA We next investigated whether or not cell surface-expressed nucleolin is a receptor for maleylated-BSA. As shown in Fig. 4A, binding of maleylated-BSA by macrophages was inhibited by anti-nucleolin antibody but not by control-rabbit IgG (Fig. 4A). Further, when nucleolin was blocked using the nucleolin-specific oligonucleotide aptamer antineoplastic guanine rich oligonucleotide (AGRO), ${ }^{24)}$ macrophage binding of maleylated-BSA was inhibited, whereas adding cytosine rich oligonucleotide (CRO) as a control had no such effect (Fig. 4B). In addition, we expressed recombinant nucleolin on the surface of non-macrophage HEK cells by transiently transfecting nucleolin on HEK cells as previously described. ${ }^{8)}$ Binding of maleylated-BSA to these HEK cells was slightly but significantly increased compared to nontransfected HEK cells ( $p$ value=0.0366) (Fig. 4C). These results indicate that nucleolin is a receptor for maleylated-BSA. 
A

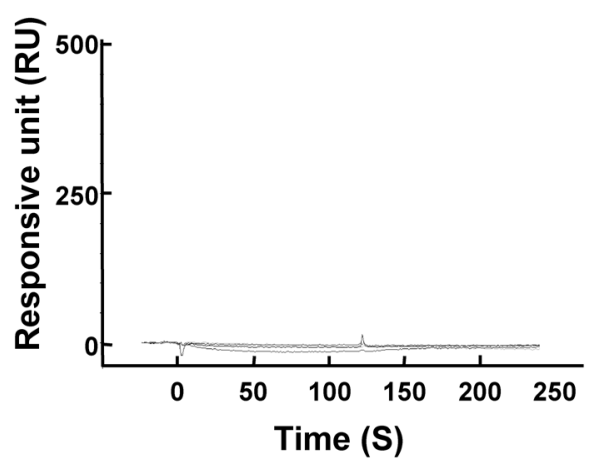

B

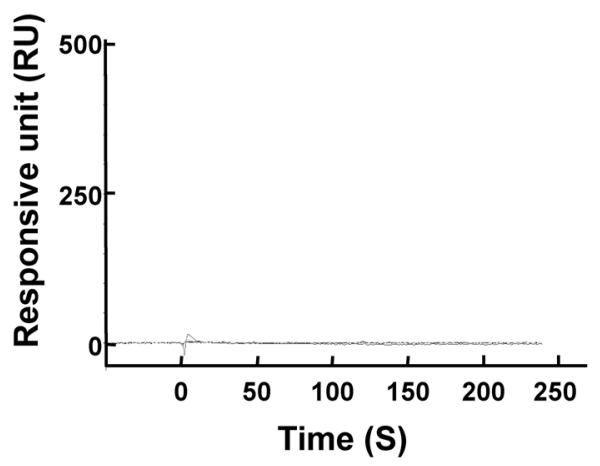

C

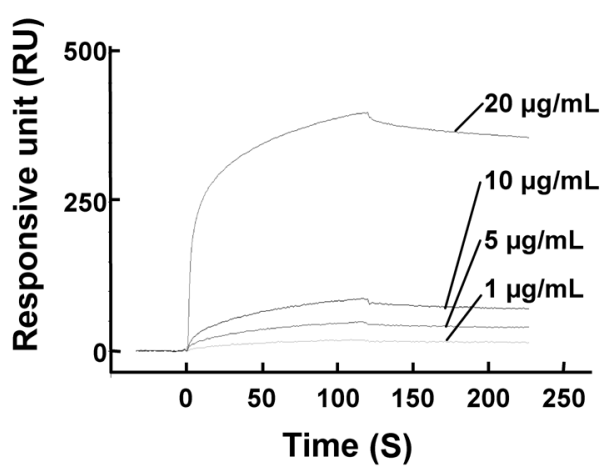

D

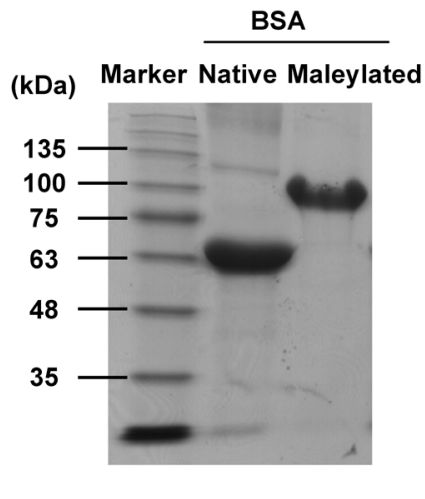

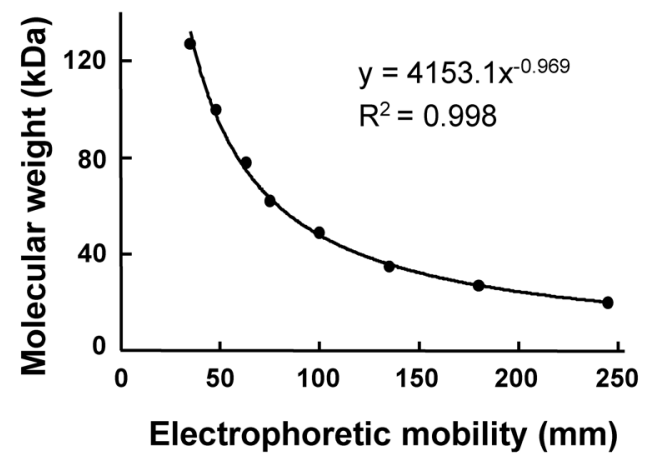

Fig. 3. Binding of Nucleolin with Maleic Anhydrade, Control-BSA, and Maleylated-BSA

Surface plasmon-resonance analyses of maleic anhydride, control-BSA, and maleylated-BSA binding to nucleolin. Control-BSA (A), maleic anhydrade (B), and maleylated-BSA (C) were washed over rNUC284-immobilized CM5 dextran-sensor chips. Maleic anhydrade, control-BSA, and maleylated-BSA were applied at $1-20 \mu \mathrm{g} / \mathrm{mL}$. An activated and blocked flow cell without immobilized ligands was used to evaluate nonspecific binding. (D) SDS-PAGE analysis of control-BSA and maleylated-BSA. Postelectrophoresis, bands were visualized by Coomassie Brilliant Blue staining (left panel). Analytical curve of molecular weight and electrophoretic mobility (right panel).

A

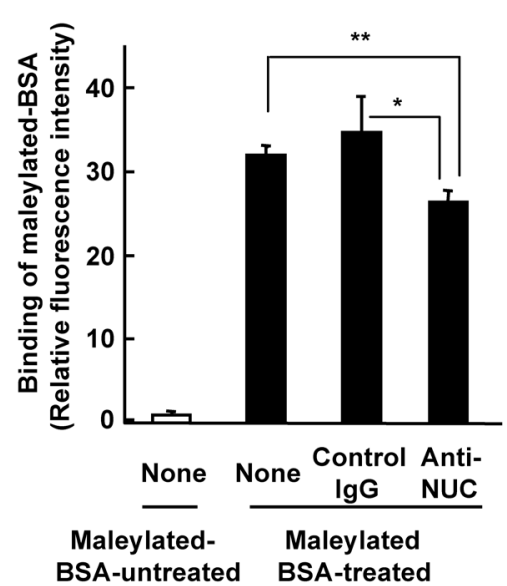

B

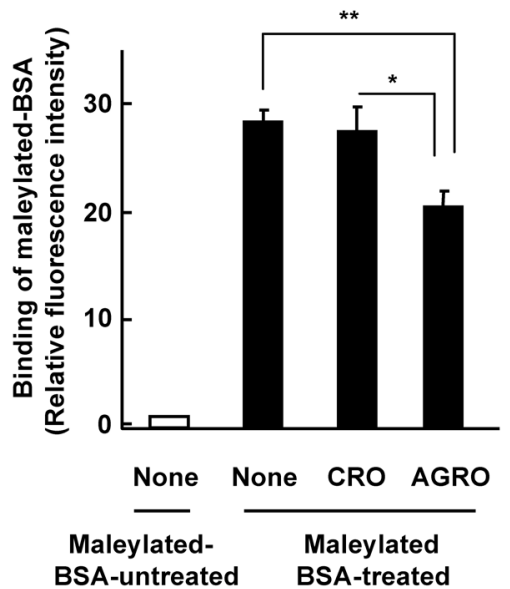

C

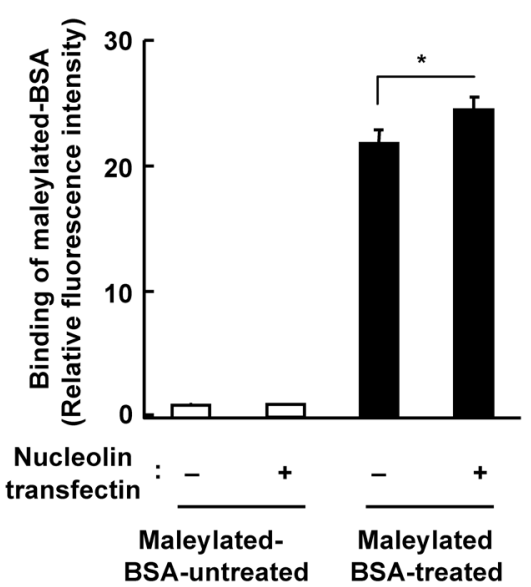

Fig. 4. Involvement of Macrophage-Surface Nucleolin in Binding of Maleylated-BSA

(A) Co-incubation with $10 \mu \mathrm{g} / \mathrm{mL}$ anti-nucleolin antibody inhibited binding of $10 \mu \mathrm{g} / \mathrm{mL}$ maleylated-BSA. (B) Co-incubation with $10 \mu \mathrm{M}$ nucleolin-specific aptamer AGRO inhibited binding of $10 \mu \mathrm{g} / \mathrm{mL}$ maleylated-BSA. (C) Binding of $10 \mu \mathrm{g} / \mathrm{mL}$ maleylated-BSA to nucleolin-transfected HEK cells. Bars represent mean \pm S.D. of triplicate determinations. $* p<0.05 ; * *<<0.01$.

\section{DISCUSSION}

Nucleolin has recently been characterized as a phagocyte receptor that initiates the removal of a variety of discarded elements. ${ }^{4,6-9,25)}$ Here, we showed that nucleolin expressed on the surface of macrophages is also a receptor for maleylatedBSA. These observations support the idea that phagocytes with cell-surface expression of nucleolin have a general scav- 
enger-like ability.

In the present study, maleylated-BSA serves as the ligand for nucleolin, while the biological impacts of the ligand on nucleolin on macrophage have remained obscure. Alford et al., reported that maleylated-BSA elicits transcription and secretion of proinflammatory cytokines, including, nitric oxide, TNF- $\alpha$, and nuclear factor-kappa B (NF- $\kappa \mathrm{B})$, suggesting that maleylated-BSA induces inflammation. ${ }^{18)}$ Although the precise mechanism of the inflammation induced by maleylated-BSA is still unknown, nucleolin might function as a receptor. Indeed, cell surface-expressed nucleolin is known to be involved in the inflammatory response induced by lipopolysaccharide. ${ }^{10)}$ In addition, TNF- $\alpha$-inducing protein $(\operatorname{Tip} \alpha)$, a carcinogenic factor released by Helicobacter pylori, induces TNF- $\alpha$ and chemokine gene NF- $\kappa \mathrm{B}$ activation through cell surface-expressed nucleolin. ${ }^{26)}$ As down-regulation of cell surface nucleolin inhibited inflammatory response, ${ }^{26)}$ an anti-inflammatory strategy that targets nucleolin might be a promising strategy for preventing inflammation.

Maleylation of BSA results in an affinity for nucleolin. Scavenger receptors generally have an affinity for polyanionic molecules (e.g. acetylated-LDL, oxidized-LDL, polysaccharides (polyvinyl sulfate, dextran sulfate and fucoidan) and polynucleotides (poly[G] and poly[C]). ${ }^{15)}$ ). The polyanionic nature of maleylated-BSA might therefore play a major role in nucleolin binding as maleylated proteins have an excess negative charge. ${ }^{16)}$ However, negative charge alone cannot explain the affinity between nucleolin and maleylated-BSA, as maleic anhydride does not have an affinity for nucleolin (Fig. 3B). In addition, the binding of rNUC284 and maleylated-BSA did not dissociate with $\mathrm{NaCl}$ treatments by SPR analysis (data not shown). In contrast, treatment with the protein-denaturing agent guanidine did dissociate binding, which indicates that the bond between nucleolin and maleylated-BSA is not only an ionic bond but also superstructural modifications due to maleylation are required.

Our previous studies revealed that nucleolin also bound to an aggregated sialylpolylactosaminyl chain of CD43, a negatively charged membrane protein on T-lymphocytes. ${ }^{8,27)}$ These studies showed that the three-dimensional structure of the CD43 cap is critical for binding to nucleolin. Therefore, negative charges might have an important role in binding between maleylated-BSA and nucleolin. In addition, the superstructure of the ligand composed by clustering or aggregation might also be important for binding to nucleolin.

As SRs play an important role in the pathogenesis of various diseases, including atherosclerosis, soluble SRs were investigated. Jalkanen et al. reported that soluble SRs inhibit receptor-mediated functions in atherosclerosis. ${ }^{28)}$ Those authors generated a secreted macrophage scavenger receptor (sMSR) that consisted of the bovine growth hormone signal sequence and the human MSR-AI extracellular domains. sMSRs reduce the degradation of atherogenic modified LDL and monocyte/macrophage adhesion on endothelial cells. In addition, adeno-associated virus (AAV)-mediated sMSR gene transfer reduced atherosclerotic lesion area in the aorta. Even though eradication of established disease was not possible, atherosclerotic lesion formation could be modified using AAVmediated gene transfer of the sMSR. ${ }^{28)}$ As nucleolin is also detected in serum, ${ }^{29)}$ nucleolin operation in vivo might also be a useful means of preventing and treating SRs-involved dis- eases, including atherosclerosis.

Here, we demonstrated that, in addition to other discarded elements, ${ }^{4,6-9,25)}$ maleylated-BSA is also a ligand for nucleolin. This observation supports the notion that nucleolin on the surface of phagocytes has a general scavenger-like ability. Additional comprehensive evaluation of nucleolin, including the molecular composition of its ligands and the functional consequences of their composition, will further clarify the physiological role of SRs.

Conflict of Interest The authors declare no conflict of interest.

\section{REFERENCES}

1) Fadok VA, Bratton DL, Henson PM. Phagocyte receptors for apoptotic cells: recognition, uptake, and consequences. J. Clin. Invest., 108, 957-962 (2001).

2) Maderna P, Godson C. Phagocytosis of apoptotic cells and the resolution of inflammation. Biochim. Biophys. Acta, 1639, 141-151 (2003).

3) Canton J, Neculai D, Grinstein S. Scavenger receptors in homeostasis and immunity. Nat. Rev. Immunol., 13, 621-634 (2013).

4) Miki Y, Dambara H, Tachibana Y, Hirano K, Konishi M, Beppu M. Macrophage recognition of toxic advanced glycosylation end products through the macrophage surface-receptor nucleolin. Biol. Pharm. Bull., 37, 588-596 (2014).

5) Feng $\mathrm{H}$, Guo L, Wang D, Gao H, Hou G, Zheng Z, Ai J, Foreman O, Daugherty A, Li XA. Deficiency of scavenger receptor BI leads to impaired lymphocyte homeostasis and autoimmune disorders in mice. Arterioscler. Thromb. Vasc. Biol., 31, 2543-2551 (2011).

6) Nigg EA. Nucleocytoplasmic transport: signals, mechanisms and regulation. Nature, 386, 779-787 (1997).

7) Ozawa D, Nakamura T, Koike M, Hirano K, Miki Y, Beppu M. Shuttling protein nucleolin is a microglia receptor for amyloid beta peptide 1-42. Biol. Pharm. Bull., 36, 1587-1593 (2013).

8) Hirano K, Miki Y, Hirai Y, Sato R, Itoh T, Hayashi A, Yamanaka M, Eda S, Beppu M. A multifunctional shuttling protein nucleolin is a macrophage receptor for apoptotic cells. J. Biol. Chem., 280 , 39284-39293 (2005).

9) Miki Y, Itoh T, Hirano K, Eda S, Hayashi A, Yamanaka M, Beppu M. Clearance of oxidatively damaged cells by macrophages: recognition of glycoprotein clusters by macrophage-surface nucleolin as early apoptotic cells. Biol. Pharm. Bull., 32, 564-572 (2009).

10) Wang Y, Mao M, Xu JC. Cell-surface nucleolin is involved in lipopolysaccharide internalization and signalling in alveolar macrophages. Cell Biol. Int., 35, 677-685 (2011).

11) Sinclair JF, O’Brien AD. Cell surface-localized nucleolin is a eukaryotic receptor for the adhesin intimin-gamma of enterohemorrhagic Escherichia coli O157:H7. J. Biol. Chem., 277, 2876-2885 (2002).

12) Bose S, Basu M, Banerjee AK. Role of nucleolin in human parainfluenza virus type 3 infection of human lung epithelial cells. $J$. Virol., 78, 8146-8158 (2004).

13) Nisole S, Said EA, Mische C, Prevost MC, Krust B, Bouvet P, Bianco A, Briand JP, Hovanessian AG. The anti-HIV pentameric pseudopeptide HB-19 binds the C-terminal end of nucleolin and prevents anchorage of virus particles in the plasma membrane of target cells. J. Biol. Chem., 277, 20877-20886 (2002).

14) de Verdugo UR, Selinka HC, Huber M, Kramer B, Kellermann J, Hofschneider PH, Kandolf R. Characterization of a 100-kilodalton binding protein for the six serotypes of coxsackie B viruses. $J$. Virol., 69, 6751-6757 (1995).

15) Hampton RY, Golenbock DT, Penman M, Krieger M, Raetz CR. Recognition and plasma clearance of endotoxin by scavenger recep- 
tors. Nature, 352, 342-344 (1991).

16) Butler PJ, Hartley BS. Maleylation of amino groups. Methods Enzymol., 25, 191-199 (1972).

17) Tada R, Koide Y, Yamamuro M, Tanaka R, Hidaka A, Nagao K, Aramaki Y. Maleylated-BSA suppresses lipopolysaccharide-induced IL-6 production by activating the ERK-signaling pathway in murine RAW264.7 cells. Int. Immunopharmacol., 19, 5-9 (2014).

18) Alford PB, Xue Y, Thai SF, Shackelford RE. Maleylated-BSA enhances production of nitric oxide from macrophages. Biochem. Biophys. Res. Commun., 245, 185-189 (1998).

19) Lowry OH, Rosebrough NJ, Farr AL, Randall RJ. Protein measurement with the Folin phenol reagent. J. Biol. Chem., 193, 265-275 (1951).

20) Habeeb AF. Determination of free amino groups in proteins by trinitrobenzenesulfonic acid. Anal. Biochem., 14, 328-336 (1966).

21) Miksa M, Komura H, Wu R, Shah KG, Wang P. A novel method to determine the engulfment of apoptotic cells by macrophages using pHrodo succinimidyl ester. J. Immunol. Methods, 342, 71-77 (2009).

22) Van Regenmortel MH. Use of biosensors to characterize recombinant proteins. Dev. Biol. Stand., 83, 143-151 (1994).

23) Laemmli UK. Cleavage of structural proteins during the assembly of the head of bacteriophage T4. Nature, 227, 680-685 (1970).

24) Mongelard F, Bouvet P. AS-1411, a guanosine-rich oligonucleotide aptamer targeting nucleolin for the potential treatment of cancer, including acute myeloid leukemia. Curr. Opin. Mol. Ther., 12, 107-114 (2010).

25) Miki Y, Tazawa T, Hirano K, Matsushima H, Kumamoto S, Hamasaki N, Yamaguchi T, Beppu M. Clearance of oxidized erythrocytes by macrophages: involvement of caspases in the generation of clearance signal at band 3 glycoprotein. Biochem. Biophys. Res. Commun., 363, 57-62 (2007).

26) Watanabe $T$, Tsuge $H$, Imagawa $T$, Kise $D$, Hirano $K$, Beppu M, Takahashi A, Yamaguchi K, Fujiki H, Suganuma M. Nucleolin as cell surface receptor for tumor necrosis factor-alpha inducing protein: a carcinogenic factor of Helicobacter pylori. J. Cancer Res. Clin. Oncol., 136, 911-921 (2010).

27) Oguri E, Miki Y, Hirano K, Yamanaka M, Beppu M. Clearance of CD43-capped cells by macrophages: capping alone leads to phagocytosis. Biol. Pharm. Bull., 35, 551-558 (2012).

28) Jalkanen J, Leppanen P, Pajusola K, Narvanen O, Mahonen A, Vahakangas E, Greaves DR, Bueler H, Yla-Herttuala S. Adenoassociated virus-mediated gene transfer of a secreted decoy human macrophage scavenger receptor reduces atherosclerotic lesion formation in LDL receptor knockout mice. Mol. Ther., 8, 903-910 (2003).

29) Liu J, Yin L, Dong H, Xu E, Zhang L, Qiao Y, Liu Y, Li L, Jia J. Decreased serum levels of nucleolin protein fragment, as analyzed by bead-based proteomic technology, in multiple sclerosis patients compared to controls. J. Neuroimmunol., 250, 71-76 (2012). 